\title{
Optimasi Hydroxypropyl Methylcellulose dan Chitosan pada Tablet Floating-Mucoadhesive Diltiazem Hidroklorida Menggunakan Desain Faktorial
}

\section{(Optimization of Hydroxypropyl Methylcellulose and Chitosan on Floating-Mucoadhesive Diltiazem Hydrochloride Tablet Using Factorial Design)}

\author{
Irsalina Triastutik, Lusia Oktora Ruma Kumala Sari, Lina Winarti \\ Fakultas Farmasi Universitas Jember \\ Jln. Kalimantan 37, Jember 68121 \\ e-mail korespondensi: oktora@unej.ac.id
}

\begin{abstract}
Diltiazem $\mathrm{HCl}$ is one of the drugs used for hypertension treatment. It requires frequent dosing, which is why diltiazem $\mathrm{HCl}$ needs to be formulated into preparations using a controlled release drug delivery system. The combination of floating and the mucoadhesive system is expected to increase the stomach's retention of the dosage form. This study aimed to determine the optimum composition of hydroxypropyl methylcellulose (HPMC K100M) and chitosan for floating mucoadhesive diltiazem $\mathrm{HCl}$ tablet. Tablets that have been prepared were evaluated for the tablet's physical characterization, powder flowability test, dissolution test, floating ability, and mucoadhesive test. Tablets were optimized using a factorial design, and the data were analyzed using design expert 11.0.0. The results showed that the optimum formula for polymer combination in diltiazem HCl tablet was $175 \mathrm{mg}$ for HPMC K100M and 50 $\mathrm{mg}$ for chitosan. The combination of polymers with this amount can produce a floating lag time of 45,333 seconds, floating duration time $>12$ hours, and the strength of mucoadhesive is 81,633 grams.
\end{abstract}

Keywords: Diltiazem HCl, HPMC K100M, chitosan, floating-mucoadhesive system, factorial design

\begin{abstract}
Abstrak
Diltiazem $\mathrm{HCl}$ merupakan salah satu obat yang digunakan untuk pengobatan hipertensi dengan memerlukan frekuensi dosis yang terlalu sering. $\mathrm{Hal}$ ini menyebabkan diltiazem $\mathrm{HCl}$ perlu diformulasi menjadi sediaan dengan menggunakan sistem pelepasan terkontrol. Kombinasi sistem floating dan mucoadhesive diharapkan dapat meningkatkan retensi sediaan dalam lambung. Penelitian ini bertujuan untuk mengetahui komposisi optimum dari kombinasi polimer HPMC K100M dan chitosan yang memenuhi persyaratan yang diinginkan dalam sediaan tablet floating mucoadhesive diltiazem $\mathrm{HCl}$. Tablet yang telah dihasilkan dievaluasi, meliputi pengujian fisik tablet, pengujian sifat alir serbuk, pengujian pelepasan obat, pengujian daya mengapung, dan pengujian daya mucoadhesive. Sedian tablet dioptimasi menggunakan desain faktorial. Data dianalisis menggunakan program statistik software design expert versi 11.0.0. Dari formula optimum didapatkan jumlah HPMC K100M $175 \mathrm{mg}$ sedangkan jumlah chitosan 50 mg. Kombinasi polimer dengan jumlah tersebut menghasilkan floating lag time selama 45,333 detik, floating duration time $>12$ jam dan kekuatan mucoadhesive 81,633 gram.
\end{abstract}

Kata kunci: Diltiazem HCl, HPMC K100M, chitosan, sistem floating-mucoadhesive, desain faktorial 


\section{Pendahuluan}

Diltiazem $\mathrm{HCl}$ merupakan penghambat kanal kalsium yang digunakan untuk mengobati angina pektoris, mengendalikan hipertensi sistemik, dan penyakit kardiovaskular lainnya. Diltiazem $\mathrm{HCl}$ diketahui memiliki frekuensi pemberian 3-4 kali dalam sehari dan mengalami first pass metabolism dengan bioavaibilitas absolutnya hanya $30-40 \%$ serta waktu paruh 3-4 jam [1]. Waktu paruh yang relatif pendek menyebabkan ketidaknyamanan pada pasien karena frekuensi pemberian harus dilakukan berulang kali sehingga dapat menyebabkan terjadinya penurunan kepatuhan pada pasien untuk meminum obat [2].

Salah satu cara untuk menanggulangi hal tersebut adalah dengan dibuatnya sediaan gastroretentive drug delivery system (GRDDS). Sistem GRDDS merupakan sistem penghantaran obat yang dirancang untuk tertahan di dalam lambung dalam jangka waktu yang lama sehingga bioavaibilitas obat akan meningkat [3]. Salah satu bentuk sistem gastroretentive yang dikembangkan adalah sistem floating dan mucoadhesive [4].

Sistem floating merupakan sistem gastroretentive yang memiliki densitas kurang dari cairan lambung sehingga dapat tetap mengapung di lambung tanpa dipengaruhi pengosongan lambung untuk jangka lama. HPMC K100M merupakan salah satu polimer yang digunakan untuk sistem floating.

Sistem mucoadhesive adalah sistem yang menggunakan polimer alami atau sintetis dan mempunyai kemampuan mucoadhesive serta mampu membuat membuat sediaan melekat pada membran mukosa [5]. Chitosan merupakan polimer yang digunakan dalam sistem mucoadhesive. Chitosan mampu membentuk lapisan gel kental saat kontak dengan cairan lambung dan dapat mengontrol pelepasan obat dengan cara difusi [6].

\section{Metode Penelitian}

\section{Alat dan Bahan}

Peralatan yang digunakan dalam penelitian ini adalah alat uji disolusi tipe dayung (Pharmeq), spektrofotometer (Genesys tipe 10S UV-Vis), alat uji kerapuhan tablet (Pharmeq tipe $T A B$ ), alat uji kekerasan tablet (Pharmeq Powder Flow Tester), timbangan analitik digital (Adventure Ohaus), mesin pencetak tablet single punch (Mini Tab), alat uji sifat alir bentuk corong (Pharmeq), alat uji mucoadhesive, stopwacth, mortir dan stamper, serta software pengolah e-Journal Pustaka Kesehatan, vol. 8 (no. 3), September 2020 data (Design Expert versi 11.0.0), $\mathrm{pH}$ meter (Elmetron CP-502), alat-alat gelas, kertas saring dan aplikasi SPPS.

Bahan yang digunakan dalam penelitian ini adalah Diltiazem Hidroklorida (Kimia Farma), chitosan (Biotech Surindo), HPMC K100M (CV. Cipta Anugerah Bakti Mandiri), avicel (PT. Brataco Chemika), natrium bikarbonat (PT. Brataco Chemika), Mg stearat (PT. Brataco Chemika), PVP K 30 (PT. Brataco Chemika), aquadest, $\mathrm{KCl}, \mathrm{HCl} 12 \mathrm{M}$, lambung kelinci jantan, dan dapar $\mathrm{HCl} \mathrm{pH} 1,2$.

\section{Pembuatan tablet floating-mucoadhesive diltiazem $\mathrm{HCl}$}

Semua bahan kecuali magnesium stearat dicampur dengan diaduk selama 10 menit. Magnesium stearat ditambahkan pada tahap akhir pencampuran dengan pengadukan selama 5 menit. Magnesium stearat sebagai lubrikan dapat melapisi permukaan serbuk sehingga mengurangi gesekan antara tablet dan dinding punch dan die. Pencampuran bahan lain dengan magnesium stearat selama 5 menit bertujuan untuk menghindari overmixing. Rancangan formula dapat dilihat pada Tabel 1.

\section{Evaluasi tablet floating-mucoadhesive diltiazem $\mathrm{HCl}$}

Tabel 1. Susunan Formula

\begin{tabular}{cccccc}
\hline Bahan & Fungsi & $\mathrm{F} 1$ & $\mathrm{~F} 2$ & $\mathrm{~F} 3$ & $\mathrm{~F} 4$ \\
\hline $\begin{array}{c}\text { Diltiazem } \\
\mathrm{HCl}\end{array}$ & $\begin{array}{c}\text { Bahan } \\
\text { aktif }\end{array}$ & $\begin{array}{c}90 \\
\mathrm{mg}\end{array}$ & $\begin{array}{c}90 \\
\mathrm{mg}\end{array}$ & $\begin{array}{c}90 \\
\mathrm{mg}\end{array}$ & $\begin{array}{c}90 \\
\mathrm{mg}\end{array}$ \\
\hline $\begin{array}{c}\text { HPMC } \\
\text { K100M }\end{array}$ & $\begin{array}{c}\text { Polimer } \\
\text { floating }\end{array}$ & $\begin{array}{c}100 \\
\mathrm{mg}\end{array}$ & $\begin{array}{c}175 \\
\mathrm{mg}\end{array}$ & $\begin{array}{c}100 \\
\mathrm{mg}\end{array}$ & $\begin{array}{c}175 \\
\mathrm{mg}\end{array}$ \\
\hline Chitosan & $\begin{array}{c}\text { Polimer } \\
\text { mucoadhesive }\end{array}$ & $\begin{array}{c}50 \\
\mathrm{mg}\end{array}$ & $\begin{array}{c}50 \\
\mathrm{mg}\end{array}$ & $\begin{array}{c}100 \\
\mathrm{mg}\end{array}$ & $\begin{array}{c}100 \\
\mathrm{mg}\end{array}$ \\
\hline PVP K 30 & Pengikat & $\begin{array}{c}25 \\
\mathrm{mg}\end{array}$ & $\begin{array}{c}25 \\
\mathrm{mg}\end{array}$ & $\begin{array}{c}25 \\
\mathrm{mg}\end{array}$ & $\begin{array}{c}25 \\
\mathrm{mg}\end{array}$ \\
\hline Natrium \\
bikarbonat & $\begin{array}{c}\text { Generating } \\
\text { agent }\end{array}$ & $\begin{array}{c}75 \\
\mathrm{mg}\end{array}$ & $\begin{array}{c}75 \\
\mathrm{mg}\end{array}$ & $\begin{array}{c}75 \\
\mathrm{mg}\end{array}$ & $\begin{array}{c}75 \\
\mathrm{mg}\end{array}$ \\
\hline Avicel & Bahan Pengisi & $\begin{array}{c}155 \\
\mathrm{mg}\end{array}$ & $\begin{array}{c}105 \\
\mathrm{mg}\end{array}$ & $\begin{array}{c}80 \\
\mathrm{mg}\end{array}$ & $\begin{array}{c}30 \\
\mathrm{mg}\end{array}$ \\
\hline Mg stearat & Lubrikan & $5 \mathrm{mg}$ & $5 \mathrm{mg}$ & $5 \mathrm{mg}$ & $5 \mathrm{mg}$
\end{tabular}

Campuran serbuk yang telah terbentuk dilakukan pengujian sifat alir dengan cara menentukan sudut diam dan waktu alir. 
Penentuan kadar diltiazem $\mathrm{HCl}$ diperoleh dari hasil penentuan panjang gelombang maksimum dari pengukuran larutan diltiazem $\mathrm{HCl} 5 \mathrm{ppm}$ dalam dapar $\mathrm{HCl} \mathrm{pH} \mathrm{1,2,} \mathrm{yang} \mathrm{dilakukan} \mathrm{dengan}$ menetapkan 5 titik konsentrasi yang berbeda secara acak.

Pencetakan tablet dilakukan dengan mencampurkan serbuk selanjutnya dikompresi menggunakan pencetak tablet single punch ( Mini Tab) dengan metode cetak langsung. Evaluasi tablet selanjutnya dilakukan dengan pengujian kekerasan tablet, pengujian kerapuhan tablet, pengujian keseragaman bobot tablet. Keseragaman bobot tablet memenuhi persyaratan jika nilai penerimaan (L1) 10 unit sediaan tidak kurang atau sama dengan L1\% yaitu $15 \%$ nilai penerimaan dapat dilihat pada persamaan 1 :

$$
\text { Nilai penerimaan }=|\mathrm{M}-\dot{x}| k s
$$

Keterangan :

$M$ : Nilai rujukan

$\dot{x}$ : rata-rata dari masing-masing kandungan

$\left(x_{1}, x_{2}, \ldots, x_{n}\right)$

$k$ : konstanta penerimaan (untuk $\mathrm{n}=10$ nilai $k$ $=2,4$ )

$s$ : simpangan baku sampel

Kemampuan floating tablet ditentukan dengan pengukuran floating lag time dan floating duration time, dilakukan dengan memasukkan tablet ke dalam larutan dapar $\mathrm{HCl}$ $0,1 \mathrm{~N} \mathrm{pH} 1,2$ sebanyak $100 \mathrm{~mL}$ dengan suhu pengujian $37 \pm 0,5^{\circ} \mathrm{C}$. Pengujian dilakukan dengan replikasi 3 tablet pada tiap formula [7].

Pengujian kekuatan mucoadhesive dilakukan dengan menggunakan alat texture analyzer (TAXT plus, Stable Micro Systems, UK) dengan cara sebagai berikut: lambung kelinci segar diletakkan dalam dapar $\mathrm{HCl} 0,1 \mathrm{~N} \mathrm{pH} \mathrm{1,2,}$ dipotong berukuran $2 \times 2 \mathrm{~cm}$. Potongan lambung kemudian direndam dalam dapar $\mathrm{HCl} 0,1 \mathrm{~N}$ $\mathrm{pH} 1,2$ dan suhu dijaga pada $37^{\circ} \mathrm{C}$. Tablet uji kemudian diletakkan pada probe (diameter 10 $\mathrm{mm}$ ), diatur dengan kecepatan rendah 0,5 $\mathrm{mm} /$ detik sampai tablet kontak dengan jaringan mukosa. Gaya konstan sebesar $500 \mathrm{~g}$ diaplikasikan selama 10 detik, kemudian ditarik dengan kecepatan $10 \mathrm{~mm} /$ detik dengan jarak 10 $\mathrm{mm}$. Puncak yang terbentuk dari gaya pelepasan digunakan untuk menentukan kekuatan mucoadhesive menggunakan texture exponent software. Pengujian dilakukan sebanyak tiga kali replikasi untuk masingmasing formula [8].

Analisis data hasil penelitian dilakukan dengan metode desain faktorial. Berdasarkan data hasil pengujian, didapatkan harga untuk masing-masing respon sehingga persamaan umum menjadi $Y=b_{0}+b_{1} X_{A}+b_{2} X_{B}+b_{12} X_{A} X_{B}$ dan didapatkan persamaan umum hubungan antara faktor (aras) dan respon (floating lag time, floating duration time, dan kekuatan mucoadhesive). Berdasarkan rumus $Y=b_{0}+$ $b_{1} x_{A}+b_{2} x_{B}+b_{12} x_{A} x_{B}$ dapat dihitung harga koefisien $b_{0}, b_{1}, b_{2}, b_{12}$. Hasil perhitungan yang diperoleh, dapat dibuat contour plot menggunakan program design expert, meliputi floating lag time, floating duration time, dan kekuatan mucoadhesive tablet diltiazem $\mathrm{HCl}$ sehingga dapat diketahui efek faktor terhadap respon dan efek kombinasi faktor terhadap respon. Contour plot yang diperoleh kemudian digabungkan menjadi overlay plot untuk mengetahui komposisi optimum kombinasi antara HPMC K100M dan chitosan yang akan digunakan sebagai eksipien pada pembuatan tablet lepas lambat diltiazem $\mathrm{HCl}$ kombinasi floating dan mucoadhesive.

Verifikasi formula optimum dilakukan dengan tujuan untuk membandingkan hasil prediksi desain faktorial dengan hasil percobaan, memiliki perbedaan yang signifikan atau tidak. Hasil uji evaluasi formulasi optimum kemudian dibandingkan dengan prediksi dari desain faktorial menggunakan pendekatan statistik uji $t$ satu sampel menggunakan IBM SPSS Statistics dengan tingkat kepercayaan $95 \%$.

Pengujian pelepasan diltiazem $\mathrm{HCl}$ dilakukan dalam media larutan dapar $\mathrm{HCl} \mathrm{pH} \mathrm{1,2}$ menggunakan konstruksi dayung dengan kecepatan $50 \mathrm{rpm}$, temperatur $37^{\circ} \mathrm{C} \pm 0,5^{\circ} \mathrm{C}$, lama pengujian $12 \mathrm{jam}$. Kadar diltiazem $\mathrm{HCl}$ 
ditentukan dengan mengukur serapannya dengan spektrofotometer, hasil serapan yang diperoleh dibandingkan dengan kurva baku. Profil pelepasan diltiazem $\mathrm{HCl}$ dari matrik tablet diperoleh dengan cara memplotkan jumlah obat yang dilepaskan dalam bentuk (\%) terhadap waktu. Dari kurva profil disolusi dihitung AUC untuk menentukan efisiensi disolusi pada menit ke-720. Hasil uji pelepasan diltiazem $\mathrm{HCl}$ dari formula optimum selanjutnya dianalisis profil pelepasannya dengan menggunakan persamaan orde nol, persamaan orde satu, dan persamaan model Higuchi.

\section{Hasil Penelitian}

Hasil pengujian sifat alir campuran serbuk menunjukkan bahwa semua formula memiliki sifat alir yang baik kecuali formula $A$ yang memiliki sifat alir yang sangat baik dan campuran serbuk semua formula dapat mengalir melalui corong.

Hasil pengujian fisik campuran serbuk dan tablet meliputi penetapan kadar, keseragaman bob ot tablet (nilai penerimaan), kekerasan tablet dan kerapuhan tablet. Hasil dapat dilihat pada Tabel 2 .

Tabel 2. Hasil pengujian serbuk dan tablet

\begin{tabular}{ccccc}
\hline & $\begin{array}{c}\text { Penetapan } \\
\text { Kadar (\%) }\end{array}$ & $\begin{array}{c}\text { Nilai } \\
\text { Penerimaan } \\
\text { (\%) }\end{array}$ & $\begin{array}{c}\text { Kekerasan } \\
\text { Tablet (Kg) }\end{array}$ & $\begin{array}{c}\text { Kerapuhan } \\
\text { Tablet (\%) }\end{array}$ \\
\hline F 1 & $\begin{array}{c}92,881 \\
\pm 1,88\end{array}$ & 1,559 & $\begin{array}{c}4,15 \\
\pm 0,47\end{array}$ & 0,012 \\
\hline F A & $\begin{array}{c}91,103 \\
\pm 0,61\end{array}$ & 2,061 & $\begin{array}{c}7,20 \\
\pm 0,34\end{array}$ & 0,004 \\
\hline F B & $\begin{array}{c}99,179 \\
\pm 0,98\end{array}$ & 2,148 & $\begin{array}{c}6,30 \\
\pm 0,67\end{array}$ & 0,007 \\
\hline F AB & $\begin{array}{c}102,247 \\
\pm 0,80\end{array}$ & 1,491 & $\begin{array}{c}4,00 \\
\pm 0,40\end{array}$ & 0,036 \\
\hline Keterangan & & &
\end{tabular}

Keterangan:

*Data disajikan sebagai rerata \pm SD $(n=3)$

**Data disajikan sebagai rerata $(n=10)$

*** Data disajikan sebagai rerata $\pm \operatorname{SD}(n=10)$

****Data disajikan sebagai rerata $(n=3)$

Hasil pengujian floating lag time, floating duration time, dan kekuatan mucoadhesive dapat dilihat pada Tabel 3.
Tabel 3. Hasil pengujian kemampuan floating dan kekuatan mucoadhesive

\begin{tabular}{|c|c|c|c|}
\hline $\begin{array}{c}\text { Formu } \\
\text { la }\end{array}$ & $\begin{array}{l}\text { Floating } \\
\text { time } \\
\text { (detik) }^{*}\end{array}$ & $\begin{array}{l}\text { Floating } \\
\text { duration time } \\
(\text { Jam })^{\star *}\end{array}$ & $\begin{array}{l}\text { Kekuatan } \\
\text { Mucoadhes } \\
\text { ive }(\mathrm{kg})^{* * *}\end{array}$ \\
\hline F 1 & $22 \pm 4,35$ & $>12$ & $\begin{array}{c}29,03 \pm \\
0,94\end{array}$ \\
\hline F A & $\begin{array}{c}45,3 \pm \\
3,78\end{array}$ & $>12$ & $81,73 \pm 4,21$ \\
\hline F B & $\begin{array}{c}62,66 \pm \\
3,05\end{array}$ & $>12$ & $77,23 \pm 4,85$ \\
\hline $\mathrm{FAB}$ & $\begin{array}{c}101,3 \pm \\
4,16\end{array}$ & $>12$ & $76,63 \pm 6,40$ \\
\hline \multicolumn{4}{|c|}{$\begin{array}{l}\text { Keterangan: } \\
{ }^{*} \text { Data disajikan sebagai rerata } \pm S D(n=3) \\
{ }^{* *} \text { Data disajikan sebagai rerata } \pm S D(n=3)\end{array}$} \\
\hline
\end{tabular}

Hasil analisis respon floating lag time dengan software diperoleh Persamaan 2.

Final Equation in Terms of Coded Factors:

$\mathrm{Y}(\mathrm{FLT})=+57,83+15,50^{*} \mathrm{~A}+24,17^{*} \mathrm{~B}+3,83^{*} \mathrm{AB}$

Final Equation in Terms of Actual Factors:

$Y(F L T)=-29,33333+0,10667^{*} h p m c$

$+0,40444^{*}$ chitosan+4,08889E-003*hpmc* chitosan

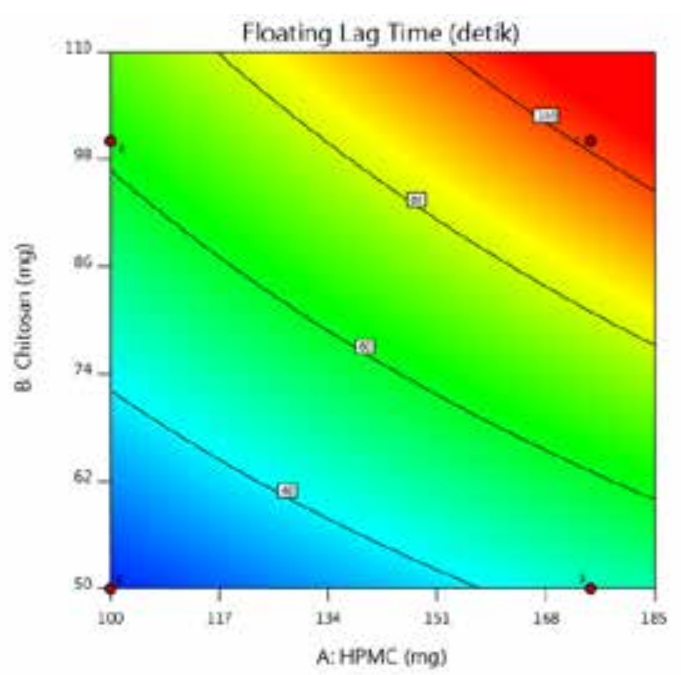

Gambar 1. Countour plot respon floating lag time

Berdasarkan Gambar 1, countour plot respon Floating lag time menunjukkan dengan meningkatnya aras HPMC dan chitosan akan menghasilkan respon yang besar pula (floating lag time yang lama) sedangkan penurunan aras dari HPMC dan chitosan akan menghasilkan respon kecil dengan kemampuan floating lag time yang cepat. 
Hasil analisis respon mucoadhesive dengan software design expert versi 11.0.0 menghasilkan Persamaan 2.

Final Equation in Terms of Coded Factor: $\mathrm{Y}($ mucoadhesive $)=+65,79+12,66^{*} \mathrm{~A}+$ $11,14^{*} \mathrm{~B}-12,96^{*} \mathrm{AB}$

Final Equation in Terms of Actual Factors: $\mathrm{Y}($ mucoadhesive $)=-156,58889+1,37422 * \mathrm{HPMC}$ $+2,34622^{*}$ Chitosan- $0,013822^{*}$ HPMC*Chitosan

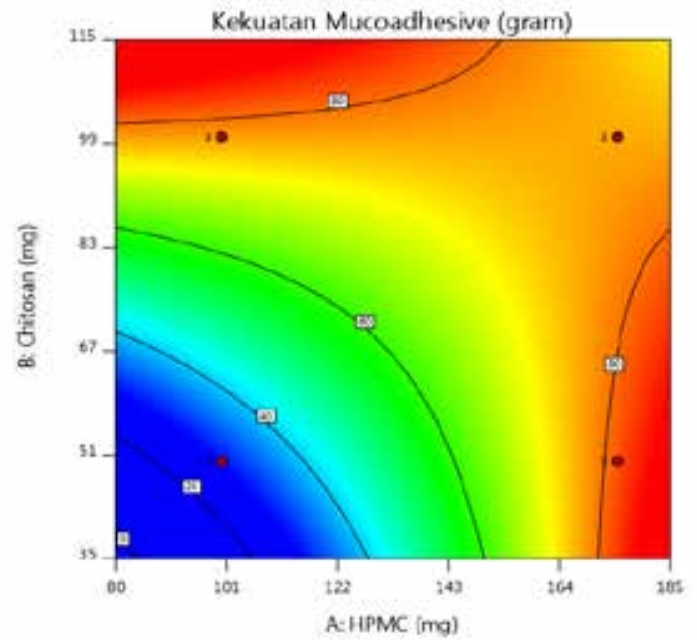

Gambar 2. Countour plot respon kekuatan mucoadhesive

Pada Gambar 2, countour plot respon kekuatan mucoadhesive menunjukkan dengan meningkatnya aras dari HPMC K100M dan penurunan aras dari chitosan maka akan meningkatkan respon kekuatan mucoadhesive dan begitu pula sebaliknya.

Penentuan daerah optimum dilakukan dengan menggabungkan overlay plot semua respon menjadi overlay plot super imposed. Daerah optimum merupakan perpotongan dari tiga daerah yang memenuhi kriteria respon floating lag time (10-600 detik), dan kekuatan mucoadhesive (50-100 gram). Hasil penentuan overlay plot formula optimum dapat dilihat pada Gambar 3.

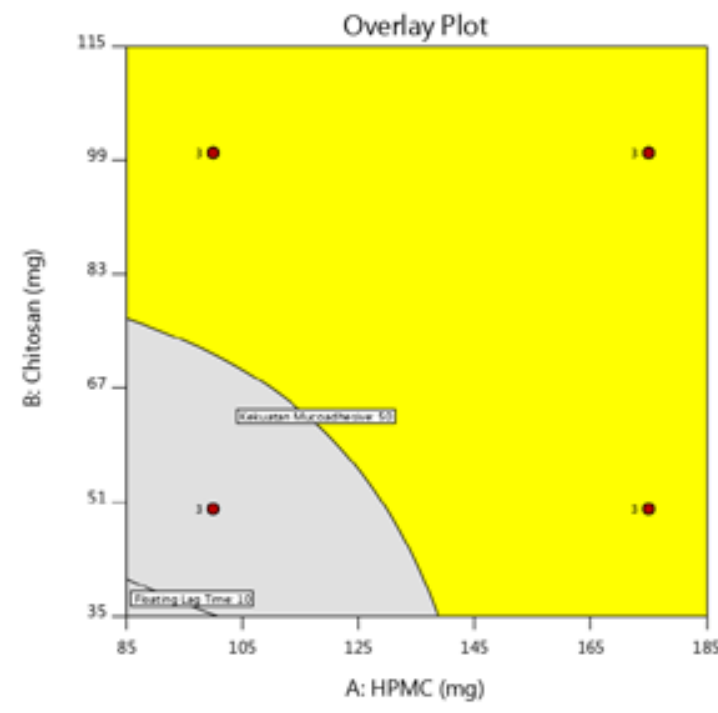

Gambar 3. Overlay plot formula optimum

Pada Gambar 3, daerah optimum ditunjukkan oleh warna kuning dengan komposisi HPMC K100M dan chitosan yang dapat memberikan respon yang diharapkan. HPMC K100M sebesar $175 \mathrm{mg}$, sedangkan chitosan $50 \mathrm{mg}$.

Formula optimum yang didapatkan dari hasil analisis design expert versi 11.0.0 selanjutnya dilakukan verifikasi kekuatan mucoadhesive, floating lag time dan floating duration time. Hasil verifikasi formula optimum yaitu formula $(A)$ seperti yang dapat dilihat pada tabel 3.

Tabel 3. Hasil signifikansi uji-t (One sample T-test)

\begin{tabular}{|c|c|}
\hline Respon & Signifikansi \\
\hline Floating Lag Time & 0,742 \\
\hline $\begin{array}{c}\text { Kekuatan } \\
\text { Mucoadhesive }\end{array}$ & 0,138 \\
\hline
\end{tabular}

Hasil percobaan dari ketiga respon seperti yang ditunjukkan pada tabel kemudian dibandingkan secara statistik menggunakan prediksi respon yang dihasilkan dari desain faktorial menggunakan uji-t (one sample T-test) dengan taraf kepercayaan $95 \%$.

Setelah dilakukan verifikasi formula optimum selanjutnya dilakukan karakterisasi formula optimum melalui pengujian pelepasan tablet. Uji disolusi in vitro memiliki tujuan untuk melihat gambaran pelepasan bahan aktif dari obat 
dalam tubuh manusia berdasarkan nilai serapan yang dihasilkan oleh spektrofotometer

Hasil pengujian disolusi selanjutnya dilakukan analisis menggunakan beberapa persamaan yaitu persamaan orde nol, persamaan orde satu dan persamaan model Higuchi, dapat dilihat pada Tabel 4.

Tabel 4. Hasil analisa kinetika pelepasan formula optimum

\begin{tabular}{|c|c|c|c|}
\hline Formula A & Orde nol & Orde satu & Higuchi \\
\hline Nilai $^{2}$ & 0,9968 & 0,9346 & 0,9968 \\
\hline
\end{tabular}

Data yang diperoleh dari uji disolusi juga digunakan untuk menghitung DE720 dari formula optimum. Hasil perhitungan DE720 ditunjukkan oleh Tabel 5.

Tabel 5. Hasil perhitungan DE720

\begin{tabular}{|c|c|}
\hline Replikasi & DE720 \\
\hline 1 & $65,327 \%$ \\
\hline 2 & $64,439 \%$ \\
\hline 3 & $64,946 \%$ \\
\hline
\end{tabular}

\section{Pembahasan}

Pada Tabel 2 didapatkan penetapan kadar diltiazem $\mathrm{HCl}$ dalam campuran serbuk dan kandungan tablet menunjukkan bahwa semua formula memenuhi rentang \% kadar bahan aktif diltiazem $\mathrm{HCl}(90,0-110,0 \%)$ dan $\mathrm{CV}$ $<6 \%$ sehingga dapat dikatakan sampel seragam [9]. Berdasarkan tabel 2 didapatkan nilai penerimaan untuk keempat formula yaitu L1 kurang dari $15 \%$ dengan pengujian 10 buah tablet yang mengindikasikan bobot tablet dari keempat formula dinyatakan seragam.

Pengujian kekuatan mekanik tablet bertujuan untuk mengetahui ketahanan sediaan tablet dalam menghadapi tekanan yang didapatkan baik ketika proses pengemasan, distribusi ataupun ketika disimpan. Hasil pengujian kekuatan mekanik tablet menunjukkan bahwa semua formula hasil memenuhi kriteria kekerasan $2-8 \mathrm{Kg}$ [10]. dan kerapuhan $<1 \%[11]$.

Parameter kemampuan mengapung yang diuji pada penelitian ini adalah floating lag time dan floating duration time. Persyaratan e-Journal Pustaka Kesehatan, vol. 8 (no. 3), September 2020 floating lag time yang dipilih yaitu antara 10-600 detik dengan tujuan bahwa tablet dapat mengapung tepat di lambung dan memberikan sifat mengapung yang baik. Persyaratan floating duration time yang dipilih adalah tidak kurang dari 12 jam. Respon yang dihasilkan kemudian diolah menggunakan software design expert versi 11.0.0

Dari Persamaan 2 diketahui bahwa efek faktor chitosan lebih dominan dibandingkan HPMC maupun interaksi keduanya yang menunjukkan bahwa meningkatnya konsentrasi chitosan dapat menyebabkan peningkatan floating lag time ( floating lag time menjadi lebih lama). Efek faktor HPMC memiliki nilai positif namun lebih kecil dari efek faktor chitosan yang menunjukkan bahwa meningkatnya konsentrasi dari HPMC menyebabkan peningkatan floating lag time menjadi lebih lama tetapi kurang dari efek faktor chitosan.

Hasil pengujian kekuatan mucoadhesive terbesar pada formula $A B$ dengan hasil formula $A>B>A B>(1)$. Hasil pengujian dapat dilihat pada Tabel 3. Respon kekuatan mucoadhesive selanjutnya dianalisis dengan software design expert versi 11.0.0.

Persamaan 3, menunjukkan bahwa Efek faktor dari interaksi lebih dominan dibandingkan efek faktor HPMC dan chitosan namun menyebabkan penurunan kekuatan mucoadhesive dan penggunaan konsentrasi tinggi HPMC menyebabkan peningkatan kekuatan mucoadhesive tablet lebih besar dibandingkan efek faktor dari chitosan maupun interaksinya.

Hasil dari uji-t (one sample T-test) pada tabel 4 didapatkan hasil yaitu kekuatan mucoadhesive $=0,138$ serta floating lag time $=$ 0,742 . Tingkat signifikansi yang diperoleh $>0,05$ dapat diartikan bahwa data tidak berbeda bermakna, sehingga dapat disimpulkan bahwa persamaan yang dihasilkan dari desain faktorial dapat memberikan prediksi respon dengan baik.

Pada tabel 5 menunjukkan bahwa $\mathrm{r}^{2}$ pada formula optimum menujukkan bahwa nilai tertinggi ditunjukkan oleh kinetika pelepasan orde nol dan model Higuchi dengan nilai $\mathrm{r}^{2}$ yang sama yaitu 0,9968 . Dapat disimpulkan bahwa formula optimum mengikuti model pelepasan orde nol dan model Higuchi.

Pada tabel 6 menunjukkan bahwa sediaan yang dibuat diharapkan dapat melepas diltiazem $\mathrm{HCl}$ secara lambat yaitu tidak kurang dari 12 jam. DE sediaan pada menit ke-720 adalah 
sebesar $64,904 \%$. Pelepasan yang lambat ini dapat dipengaruhi oleh polimer yang digunakan yaitu. HPMC membentuk lapisan gel ketika kontak dengan cairan lambung, sehingga pelepasan akan lebih lambat karena diltiazem $\mathrm{HCl}$ akan berdifusi secara perlahan melewati lapisan gel ini [12].

\section{Simpulan dan Saran}

Hasil penelitian menunjukkan bahwa penggunaan polimer HPMC dan chitosan dapat meningkatkan respon floating lag time dan kekuatan mucoadhesive, namun HPMC lebih berperan dibandingkan chitosan dalam meningkatkan kedua respon tersebut. Interaksi polimer HPMC dan chitosan dapat meningkatkan floating lag time namun menurunkan respon kekuatan mucoadhesive. Kombinasi HPMC dan chitosan untuk memperoleh respon optimum pada tablet floating-mucoadhesive diltiazem $\mathrm{HCl}$ yaitu HPMC $175 \mathrm{mg}$ dan chitosan $50 \mathrm{mg}$ dengan prediksi floating lag time 45,333 detik, floating duration time $>12$ jam dan kekuatan mucoadhesive 81,633 gram.

Saran yang dapat diberikan oleh peneliti adalah penelitian selanjutnya dapat menguji batasan maksimum jumlah HPMC K100M maupun chitosan yang menghasilkan respon optimum dan dilakukan pengujian in vivo formula optimum untuk mengetahui bioavailabilitas dan profil farmakokinetika obat yang sebenarnya.

\section{Daftar Pustaka}

[1] Narayana CR, Bera D, Sakhia D, Manavadaria $\mathrm{K}$, dan Shetty NG. Formulation and evaluation of bilayer floating tablets of diltiazem hydrochloride for bimodal release. International Journal of Research in Pharmaceutical Sciences. 2012. 3(2):301306.

[2] Suresh SM, PM V, R. T, dan Malothu R. Formulation and evaluation of gastroretentive floating tablets of losartan potassium. International Journal of Biopharmaceutics. 2013. 4(1):18-26.
[3] Chaudhary $H$, Rohilla A, Rathee $P$, dan Kumar V. Optimization and formulation design of carbopol loaded piroxicam gel using novel penetration enhancers. International Journal of Biological Macromolecules. 2013, 55:246-253

[4] Sulaiman TNS, Fudholi A, dan Nugroho AK. Optimasi formula tablet gastroretentive ranitidin hcl dengan sistem floating. Majalah Farmasi Indonesia. 2011. 22(2):106-114.

[5] Carvalho F, Bruschi M, Evangelista $R$, Gremiao M, Shaikh R, Raj Singh TR, Garland MJ, Woolfson AF, dan Donnelly. RF Mucoadhesive drug delivery systems. Brazilian Journal of Pharmaceutical Sciences. 2011. 46 (1) 1-16

[6] Rowe RC, Sheskey PJ, dan Quinn ME. Handbook Of Pharmaceutical Excipients. Edition Sixth. London: Pharmaceutical Press. 2009.

[7] Fouladi F. dan Mortazavi SA. Preparation and in-vitro evaluation of gastroretentive bupropion hydrochloride tablets. Tropical Journal of Pharmaceutical Research.2012. 13 (3): 351-359

[8] Arora G, Malik K, Singh I, dan Arora S. Formulation and evaluation of controlled release mucoadhesive matrix tablets: assessment of myrrh oleo gum resin as a natural pharmaceutical excipient. International Journal of Pharmaceutical Sciences and Drug Research. 2011. 3(2):84-88.

[9] Kemenkes RI. Farmakope Indonesia Edisi V.Jakarta: Kementrian Kesehatan RI. 2014.

[10] Streubel A, Siepmann J, dan Bodmeier R. Gastroretentive drug delivery systems. Expert Opin. Drug Deliv. 2006. 3(2):217-233.

[11] Lachman L, Lieberman HA, dan Kanig JL. Teori Dan Praktek Farmasi Industri Edisi Ketiga. Jakarta: Universitas Indonesia Press. 1994.

[12] Bhise KS, Dhumal RS, Chauhan B, Paradkar A, Kadam SS. Effect of Oppositely Charged Polymer and Dissolution Medium on Swelling, Erosion, and Drug Release From Chitosan Matrices. AAPS PharmSciTech. 2007. Vol. 8 (2). 